\title{
Commentary: Biologic versus mechanical valves: Wandering in the dark
}

\author{
Donald D. Glower, MD
}

\footnotetext{
From the Division of Cardiothoracic Surgery, Department of Surgery, Duke University Medical Center, Durham, $\mathrm{NC}$

Disclosures: Author has nothing to disclose with regard to commercial support.

Received for publication Oct 18, 2018; accepted for publication Oct 18, 2018; available ahead of print Nov 17 2018.

Address for reprints: Donald D. Glower, MD, Duke University Medical Center, Box 3851, Durham, NC 27710

(E-mail: Glowe001@mc.duke.edu).

J Thorac Cardiovasc Surg 2019;158:715

0022-5223/\$36.00

Copyright (C) 2018 Published by Elsevier Inc. on behalf of The American Association for Thoracic Surgery https://doi.org/10.1016/j.jtcvs.2018.10.094
}

In this issue of the Journal, Diaz and colleagues ${ }^{1}$ present a meta-analysis of 4 propensity score-matched studies and 1 randomized trial comparing long-term outcomes in 4686 patients aged 50 to 70 years according to whether they underwent mechanical or bioprosthetic aortic valve replacement. Diaz and colleagues ${ }^{1}$ report a slight but statistically significant survival advantage with mechanical valves and conclude that this provides robust evidence supporting use of mechanical valves in this age group.

The choice of biologic versus mechanical prostheses for valve replacement has been controversial for decades. Predominant preference for one versus the other has varied from decade to decade, largely on the basis of available technology. Today, biologic valves may be favored because newly available novel oral anticoagulants are replacing warfarin for patients who have other indications for anticoagulation. The advent of valve-in-valve replacement of a failed biologic prosthesis with a transcatheter biological prosthesis has in fact prompted a change in the 2017 American College of Cardiology and American Heart Association guidelines to state that, for patients between 50 and 70 years of age, it is reasonable to individualize the choice of mechanical or bioprosthetic valve prosthesis. ${ }^{2}$ For these reasons, and perhaps others, recent usage in the United States has increasingly favor biologic aortic valve prostheses. In contrast to recent enthusiasm for bioprostheses, the analysis of Diaz and colleagues ${ }^{1}$ suggests that use of mechanical valves in patients aged 50 to 70 years is not unreasonable.

The meta-analysis of Diaz and colleagues ${ }^{1}$ is certainly not definitive, despite validation by propensity-adjusted retrospective data and a single small randomized trial. Even propensity-score analysis cannot entirely correct for unmeasured selection bias in retrospective studies, especially for such variables as medication noncompliance, history of cancer, thoracic radiation, cirrhosis, frailty, or mental disease. Even randomized trials by design examine a selected subset of the population, and results may not apply to individual patients atypical of the study population. The presented data also have limited follow-up (mean of

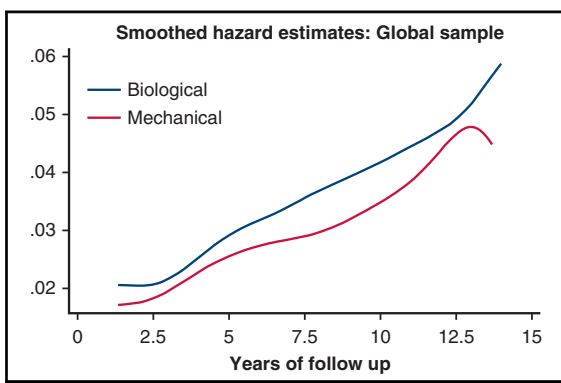

Smoothed hazard function after aortic valve replacement ( $P=.012$ by log-rank).

\section{Central Message}

Because choice of biologic versus mechanical valve prostheses inherently extrapolates from very limited data, decisions ultimately must be made by individual patients and individual physicians.

See Article page 706.
$<10$ years), especially given that reoperation on bioprostheses tends to occur after 10 to 20 years. Adequately powered randomized trials with follow-up out to the 30-year life expectancy of a 50-year-old patient are not available. At present, we have essentially no data regarding the outcome of transcatheter valve-in-valve reoperation beyond 5 years. Finally, it is not clear that valve-in-valve reoperation will ever be helpful for patients receiving 21-mm or smaller bioprostheses at initial operation.

Like the 2017 guidelines, this study extrapolates from very limited data into a future that is largely unknown. Decisions ultimately must be made by individual patients and individual physicians with imperfect data. The patients themselves vary considerably, but many prefer short-term safety to potential long-term risk. Even if we were to obtain longer-term data, these data would inherently be limited by then-outdated technologies. Thus, when it comes to choosing biologic versus mechanical aortic prostheses, we may always be wandering in the dark.

\section{References}

1. Diaz R, Hernandez-Vaquero D, Alvarez-Cabo R, Avanzas P, Silva J, Moris C, et al Long-term outcomes of mechanical versus biological aortic valve prosthesis: systematic review and meta-analysis. J Thorac Cardiovasc Surg. 2019;158:706-14.e18.

2. Nishimura RA, Otto CM, Bonow RO, Carabello BA, Erwin JP III, Fleisher LA, et al. 2017 AHA/ACC focused update of the 2014 AHA/ACC guideline for the management of patients with valvular heart disease: a report of the American College of Cardiology/American Heart Association task force on clinical practice guidelines. J Am Coll Cardiol. 2017;70:252-89. 